\title{
IS COVID-19 PREPAREDNESS AND ANXIETY CORRELATED? EMERGING DISEASE OUTBREAKS IN THE THAI CONTEXTS
}

\author{
Prasopchai Pasunon ${ }^{1}$, Afifi Lateh ${ }^{2}$, Kiflan Dolah ${ }^{3}$, Panida Kongjam ${ }^{4}$, Saminee Chemae ${ }^{5}$, Phanupong \\ Panomwan $^{6}$ and Alawee Lateh ${ }^{7}$ \\ ${ }^{1}$ Faculty of Management Sciences, Silpakorn University Petchaburi IT Campus, Petchaburi, Thailand \\ ${ }^{2}$ Faculty of Education, Prince of Songkla University Pattani Campus, Pattani, Thailand \\ ${ }^{3}$ Naradhiwas Rajanagarindra Hospital, Narathiwat, Thailand \\ ${ }^{4}$ WHO/TDR Collaborating Project, Thammasat University Rangsit Center, Pathum Thani, Thailand \\ ${ }^{5}$ Pattani Hospital, Pattani, Thailand \\ ${ }^{6}$ Office of the Education Council, Bangkok, Thailand \\ ${ }^{7}$ Faculty of Management Sciences, Prince of Songkla University Hatyai Campus, Songkhla, Thailand
}

Corresponding author: Afifi Lateh

Email: afifi.l@psu.ac.th

\begin{abstract}
It has been almost a half year since COVID-19 has forced all nations to speed up their outbreak preparedness as it simultaneously created significant public anxiety. This study investigated the canonical relationship between factors of COVID-19 preparedness and anxiety and proposed a conceptual model framework on these factors in the contexts of Thailand. This mixed-methods study employed an explanatory sequential design to conduct a two-phase exploration. Quantitative data were collected in the first phase using online questionnaires. The sample included 2808 respondents selected through a convenience and a snowball sampling. Data collection was conducted from March 29 to May 16, 2020, and content analysis was employed to process these data. The quantitative analysis with canonical relationship between COVID-19 preparedness and anxiety was 0.403 at a moderate level ( $p$-value $<0.01)$. Thai citizens with high preparedness on risk mitigation and long-term outbreak mitigation planning tended to congruently demonstrate high anxiety towards responses of the government and public sectors, corruption, and misconduct. The conceptual model framework of qualitative analysis on preparedness were classified into three levels, i.e., individuals, families and communities, and social networks. COVID-19 anxiety that was related to a) responses of the government and public sectors, and b) corruption and misconduct, and also showed direct impacts on work and life anxiety. Thai citizens recognized and understood that self-reliance is mostly needed to relieve pandemic-related anxiety. Cooperation with public and private bodies on precautionary measures was deemed essential to prevent a second wave of spread.
\end{abstract}

Keywords: anxiety, COVID-19, mental healthcare, preparedness, Thai citizen

\section{INTRODUCTION}

Amid at controlling COVID-19 spreads around the world, a new term of "New Normal" emerged based on speculation of what the world society might encounter through post-crisis changes. Suwannik predicted that three new phenomena could surface: 1) deglobalization which would rapidly transform global supply chains, e.g., inward-looking policies and protectionism, 2 ) inequality in public health which is a structural problem that requires solving, and 3) fully digital societies that revolutionize consumer behaviors ${ }^{1}$. Ali et al reported social inequality arising from COVID-19, highlighting that professionals in some occupation groups were unable to work from home, and many jobs were on hold or terminated as businesses in several industries were forced to shut down. Consequently, this economic hardship immediately posed financial risks. Furthermore, those in ethnic minorities and marginalized groups are more prone to infections due to the longstanding structural problems of social inequality, health inequality, and genetic immunity among the vulnerable ${ }^{2}$. McGreal also described this coronavirus as the "inequality virus"3.
Furthermore, Fagherazzi presented some insights on COVID-19 digital health ecosystems utilizing digital channels, including Al virtual hospitals and remote patient monitoring systems. These ecosystems encourage the public to use online media to educate themselves about self-care, health care access, and treatment guidelines. Nevertheless, it was also noted that those who could not access such information must not be neglected ${ }^{4}$.

Negative social and economic impacts of COVID19 have proven to be severe, with a low tendency for recovery. Hassan et al conducted a discourse analysis of financial statement reports of various companies worldwide (i.e., over 11,943 companies in 84 countries) from January 2001 to March 2020 and disclosed that, during the first three months of 2020, companies across the globe were discussing increased risks from the virus. The most concerning issues were reduced consumer demand, followed by uncertainty, disrupted manufacturing from interrupted raw-material supplies, crippled productivity, and labor welfare, respectively. In the short run, many social studies on COVID-19 have begun to roll out ${ }^{5}$. For instance, 
Atkeson developed SIR model (SusceptibleInfectious-Recovered) to predict the situation in the United States by classifying the population into three groups: 1) Susceptible (S) which refers to the uninfected who might be vulnerable to disease contraction, 2) Infectious (I) which refers to those who have symptoms and can spread the infection, and 3) Recovered (R) which refers to those who are immune to the disease and cannot be reinfected, or died. The prediction from this model is when the group of active infections in the population exceeds $1 \%$ the health system is forecast to be severely challenged and $10 \%$ the result in severe staffing shortages affect key financial and economic infrastructure ${ }^{6}$. Subsequently, Suwanprasert proposed SEIR model with adding the group of exposed $(E)$ which refers to those do not show symptoms but are harboring the pathogen and can transmit the disease, the model classified into seven groups by age to explain caution behaviors and revealed that people became more cautious as the risk of infection or death increased. Although the proportions of infected older adults temporarily spiked, the figures sharply decreased as they became more cautious than other groups. On the contrary, the numbers of young patients went higher and declined more slowly as the mortality rate for youths seems lower, causing them to behave less cautiously?

Thailand has suffered from the tsunami and the avian influenza in the short-term crises, and they are unlike the rapid and widespread outbreak of COVID-19. More importantly, the situation has revealed no sign of recovery nor controllability. Since it is an emerging disease, no specific country should solely bear a burden to mitigate the crisis. It is a shared responsibility and a challenge of humanity to cope with the disaster, which has the potential to generate economic, social, and livelihood impacts. In terms of social factors, past studies on 2003 SARS preparedness are worth investigating. Firstly, Bai et al examined the stress levels of 338 employees in Taiwan hospitals who were and were not quarantined. Results showed that $20 \%$ of them felt socially stigmatized or disapproved, and $9 \%$ indicated a desire to resign from their positions ${ }^{8}$. Secondly, Lau et al discovered that over $60 \%$ of locals in Hong Kong gained more attention from their families, and $30-40 \%$ of them received more support from friends and families ${ }^{9}$. Finally, Peng et al reported that older adults in Taiwan who were over 50 years old with high school education were the group with higher preparedness and more personal experiences with the epidemic than others. Hence, they suffered a more damaging mental consequence ${ }^{10}$.

The results from the survey by Prince of Songkla University Pattani Campus, which stated that $91 \%$ of the respondents were worried about COVID-19 information overload, and found that those with lower income suffered lower anxiety or mental impacts than those with higher income, which is contrastive to the results of this study ${ }^{11}$. The results are consistent with Roy et al which discovered that Indian citizens were possessed high levels of anxiety. Furthermore, over $80 \%$ of these citizens were preoccupied with the COVID19 outbreak $^{12}$. Wang et al many reportedly had moderate to severe psychological effects (53.8\%), developed symptoms with moderate to severe depression, (16.5\%), and demonstrated moderate to severe levels of anxiety $(28.8 \%)$ and stress $(8.1 \%)$, respectively ${ }^{13}$. Zhang and Ma reported that most of the Chinese citizens in Liaoning were slightly stressed out due to the outbreak, and only $7.6 \%$ demonstrated severe depression ${ }^{14}$.

Furthermore, Lekfuangfu et al investigated labor impacts from the pandemic in Thailand by categorizing Thai laborers based on flexibility in the changes of workplaces and indexing work characteristics based on worker densities. It was found that $31.5 \%$ of the Thai workers had to work with machines directly and could not work a communication-technology solution. When comparing male and female laborers, more male workers were on these machines than females. Therefore, the tendency for them to be affected was congruently also higher than female workers. The workers who were 46 years and older, tended to struggle more when working via communication technology. As a result, they suffered from technological adjustments while working at home. The least affected group was those with a bachelor's degree or higher because not only their work patterns allowed them to work from home, but their technological capacities seemed to be adequate for the adjustments. Thailand initiated a lock-down in March, and approximately 1.6 million employees earning less than 12,000 baht per month were mostly affected. Examples of mostly affected occupations included cleaning employees, restaurant attendants, kindergarten teachers, tour guides, and dentists ${ }^{15}$. However, Deeod discovered that food delivery occupations have recently generated increased remunerations as the public preferred not to risks leaving their homes. However, those on the food delivery services were reportedly concerned about economic difficulties the most, followed by social problems and health complications, respectively. Moreover, they demonstrated the highest rate of dissatisfaction in state measures for pandemic prevention, followed by high rates of dissatisfaction in state administration and access to state information and measures, respectively ${ }^{16}$. Suwanaphant et al disclosed that factors related to students' perceived risks of COVID-19 and selfprotection behaviors were associated with depression from the COVID-19 outbreak ${ }^{17}$.

Wae reported on the Thais' preparedness for the COVID-19 outbreak and found that some of the population had accurate knowledge of the disease's channels of transmission (30.9\%), hygienic hand washing $(69.0 \%)$, precautions for 
coughing and sneezing (55.2\%), and correct methods to wear surgical masks (80\%). Moreover, most Thais $(98.5 \%)$ could look up or had access to information; would immediately visit doctors and make protection-related decisions against the pandemic when showing symptoms of fever, coughing, sore throat, runny nose, shortness of breath, and exposure to suspected individuals at risk of COVID-19 (99.3\%); would inform caring medical staff when suspecting that they have come in contact with someone with COVID-19 (99.7); and would go outside to visit places when they have no indicating disease-spreading symptoms $(77.1 \%)^{18}$. Kleechaya, a study on emerging diseases, revealed that the public seemed to usually remain alert when there is an imminent risk of disease and when they are in an epidemic area. They became initially cautious when receiving news about an outbreak, but this alertness level tended to decrease over time when mass media stopped distributing relevant news. Nonetheless, locals had access to two communication channels to receive information about incoming emerging diseases from foreign soils, which were through news by mass media and official public health units. The communication involved distributing information to promote recognition of disease severity, stimulate behavioral changes, inform disease-related knowledge, and offer self-conducted safety measures $^{19}$.

When considering psychological preparedness as an ability to manage and cope with one's emotional response during a disaster, with the purpose of bettering one's cognitive and behavioral response, and widely employed classification of disaster preparedness has three categories: 1) Material Preparedness, 2) Planning Activities, and 3) Knowledge and Skills ${ }^{20}$. Whereas anxiety is one of a range of emotions that serves the positive function of alerting us to things we might need to worry about: things that are potentially harmful. More importantly, these emotions help us to evaluate potential threats and respond to them in an appropriate way, perhaps by quickening our reflexes or focusing our attention $^{21}$. Past studies related to psychological preparedness and anxiety are worth investigating, such as reported from Hauksdottir et al who examined the impact of a widower's preparedness before his wife's death from Cancer on his risk of long-term morbidity, it found that men aged 3861 years with degree of preparedness at the time of their spouse's death had increased risk of psychological morbidity and other symptoms, such as anxiety, a heightened startle response, emotional numbness, little or no grief resolution and sleep disorders, 4-5 years after the loss. For older widower's (aged 62-80 years), a low degree of preparedness increased the risk of having repeated painful memories and a heightened startle response at follow-up ${ }^{22}$. Cagle and Kovacs discovered the perceptions of preparedness and support of the informal caregivers of hospice oncology patients, they interpreted preparedness broadly and identified multiple sources of support including hospice personnel, family, friends, neighbors, and spiritual beliefs. Additionally, informational support, such as education, information, and enhanced communication were considered essential for preparing and supporting caregivers $^{23}$. Mutianingsih et al found the relationship between psychological preparedness and anxiety of the elderly in earthquake prone $\operatorname{areas}^{24}$.

Considering the disease outbreak, after Thai Minister of Public Health declared COVID-19 as a dangerous communicable disease following the Communicable Disease Act BE 2558 (2015) on February 29, $2020^{25}$ and has been implementing is "social distancing," which is through a governmental measure known as "stay at home, stop the infection, for the nation ${ }^{26}$. Although public agencies in Thailand are reasonably prepared to handle the COVID-19 pandemic, many Thais remain anxious about the situation. More specifically, the general public is concerned about the issued public measures to counteract with the outbreak, the levels of awareness of others, and future living adjustments. The immediate solutions of Thai citizens to the public's problems against the outbreak were: They have been attempting to prepare with autonomously, e.g., by producing their own masks and alcohol gel ${ }^{27}$, donating consumer items, artists and celebrities donating money to hospitals, groups of volunteers "giving away free food," and groups of volunteers giving up their accommodations such as hotels to establish field hospitals ${ }^{28}$, etc.

Although studies have been predicting and planning to handle situations such as COVID-19 and modern technology, medicines, and knowledge are accessible, the COVID-19 outbreak remains its rapid pace of spreading as this emerging disease appears to be a century extraordinary. Consequently, many industries (e.g., airlines, hotels and related services, and restaurants) remain crippled with no tendency for recovery. Although global citizens currently have access to alternative online lifestyles that involve making online financial transactions and online shopping, many industries (e.g., education and tourism) are still in shock on the requirements for grand-scale adaptations. These impacts and consequences have led to several unexpected phenomena in Thai and global communities. Under speculation that the outbreak might continue to escalate during the second half of 2020, data on COVID-19 preparedness and anxiety were collected from March 29 to April 3, 2020. The aims were to extract factors of such preparedness and anxiety (not aim to clinical anxiety disorder) in the Thai contexts through exploratory analysis and two-factor relationship analysis. How would the results differ from past outbreaks of emerging diseases? Furthermore, a conceptual model framework was proposed 
covering the factors of this preparedness and anxiety. The framework was constructed to offer vivid information visualization that might be beneficial as knowledge foundations for future handling and problem-solving.

\section{RESEARCH OBJECTIVES}

1. To analyze factors of COVID-19 preparedness of the Thai citizens

2. To analyze factors of COVID-19 anxiety of the Thai citizens

3. To analyze the canonical relationship between the factors of COVID-19 preparedness and anxiety of the Thai citizens

4. To construct and propose a conceptual model framework on the factors of COVID-19 preparedness and anxiety

\section{METHODS}

This mixed-methods study implemented an explanatory sequential design ${ }^{29}$ to analyze the relationship between COVID-19 preparedness and anxiety in the Thai contexts and the data were collected in two phases. As elaborated in Figure 1 , Phase 1 utilized an online questionnaire that was developed to explore COVID-19 preparedness and anxiety among Thai-citizen samples. Subsequently, the data were analyzed to extract a new set of factors that emerged from the response items on the preparedness and anxiety as well as identify the relationship between these two factors. Phase 2 began with the development of a semi-structured questionnaire for use with the key informants in the focus group discussions. The derived data were analyzed to construct the conceptual model framework on the factors. Details on research procedures are as elaborated in Table 1.

\section{Phase 1: The Quantitative Study}

The population included $66,558,935$ Thai citizens in 77 provinces $^{30}$ and $37,805,475$ internet users who were expected to be able to complete the constructed online questionnaires, which totals $56.8 \%$ of the entire population ${ }^{31}$. The sample size, based on the Yamane's formula with an error margin of $2 \%$, was 2,500 Thai citizens in 77 provinces who were projected to have access to the constructed online questionnaires. The sample with returned and complete questionnaires included 2,808 respondents who were selected with a convenience sampling, and a snowball sampling in which the researcher shared the questionnaire via a personal Facebook wall and the sharing reached 190 other users. The survey was conducted through this URL: https: / / forms.gle/MwzsHJiCRePF7fvZ8 from March 29 to April 3, 2020. Valid respondents included those who gave consent and expressed willingness to participate in this study.
The instrument was a three-sectioned online questionnaire, which included Section 1 with response items on demographic data, i.e., sexes, ages, education levels, and occupations residing provinces, characteristics of family members, income adequacy, and conditions of regular work or off-house errands. Section 2 comprised 24 response items on COVID-19 preparedness using a five-point Likert scale where 5 represents the most important and 1 represents the least important. Section 3 comprised nine response items on COVID-19 anxiety using a ten-point Likert scale where 10 represents the most anxious and 1 represents the least anxious (This research is not aimed at measuring clinical anxiety disorder). This section of the instrument was developed based on guidelines for self-assessment of patients, other relevant medical examples, and psychological opinions extracted from expert suggestions. The instrument was validated by three experts, and it demonstrated an $10 \mathrm{C}$ range of $0.67-1.00$. Subsequently, it was pilot tested with 30 respondents and showed a Cronbach's Alpha of 0.84 and 0.81, respectively.

On analyses, the data were firstly analyzed in frequency and percentage to present the demographic facts. Secondly, an orthogonal varimax factor was implemented to analyze the factors of COVID-19 preparedness and anxiety of the Thai citizens. Each response item was reported in mean and standard deviation. Thirdly, a canonical correlation analysis, was conducted to identify the relationship between the factors of COVID-19 preparedness and anxiety using factor scores.

\section{Phase 2: The Qualitative Study}

After the factor analysis and the canonical correlation analysis were employed, the extracted factors of and the resulting canonical relationship between COVID-19 preparedness and anxiety were further used to construct the conceptual model framework through the focus group discussions involving 15 participants divided into three groups. The first group contained five lecturers in higher education with experiences in crisis-related research, the second group contained four medical professionals on duties to handle the outbreak, the third group included two teenagers, two adults, and two older adults, who were willing to provide information and affected by the lockdown. The sessions were conducted via the Zoom application on May 10 and 16, 2020. Consents on participation and information sharing were given via telephone or online communication channels. Once 
consented, the meeting dates and times were scheduled. Before these sessions, the predetermined questions were preliminarily sent to the participants as a process to preserve individual privacy, prevent exposing them to risks and damages, maintain fairness, and protect their confidentiality.

The three questions are as follows: 1) How significant and correlated are COVID-19 preparedness and anxiety? 2) How substantial and correlated are COVID-19 anxiety and rates of spread? 3) What should be the appropriate self-practice guidelines to follow amid the COVID-19 outbreak, new normal, and next normal?

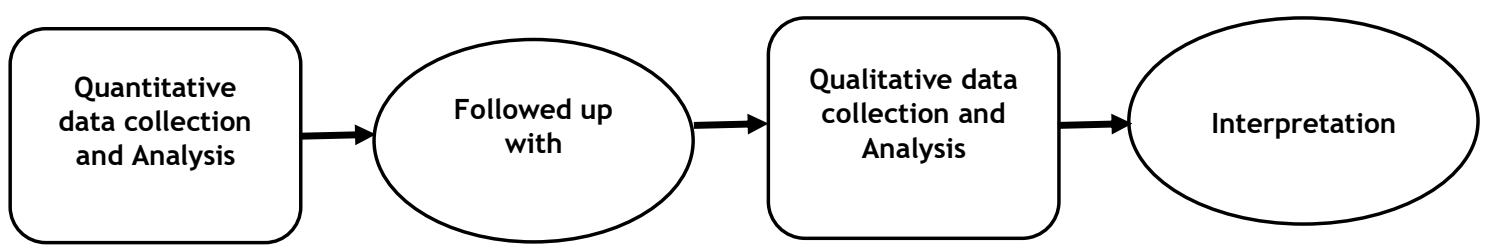

Figure 1: The study design to analyze the relationship between COVID-19 preparedness and anxiety in the Thai contexts.

Table 1: Research procedures to analyze the relationship between COVID-19 preparedness and anxiety in the Thai contexts.

\begin{tabular}{|c|c|c|}
\hline \multirow{2}{*}{$\begin{array}{l}\text { Phase } \\
\text { Phase } 1\end{array}$} & \multirow{3}{*}{$\begin{array}{ll}\text { Procedure } \\
\text { - } & \text { Development a } \\
& \text { questionnaire } \\
\text { - } & \text { Random Thai-citizen samples } \\
\text { - } & \text { COVID-19 preparedness and } \\
& \text { anxiety evaluation } \\
\end{array}$} & \multirow{3}{*}{$\begin{array}{l}\text { Outcome } \\
\text { - Online questionnaire to } \\
\text { explore COVID-19 } \\
\text { preparedness and anxiety } \\
\text { among Thai citizens }\end{array}$} \\
\hline & & \\
\hline $\begin{array}{c}\text { Quantitative Data } \\
\text { Collection }\end{array}$ & & \\
\hline & \multirow[t]{3}{*}{$\begin{array}{l}\text { - Descriptive statistics } \\
\text { - Factor analysis } \\
\text { - Canonical correlation } \\
\text { analysis }\end{array}$} & \multirow{3}{*}{$\begin{array}{l}\text { - Frequency, percentage, } \\
\text { mean and standard } \\
\text { deviation } \\
\text { - A new set of factors that } \\
\text { emerged from the response } \\
\text { items on the preparedness } \\
\text { and anxiety } \\
\text { - The relationship between } \\
\text { the preparedness and } \\
\text { anxiety }\end{array}$} \\
\hline $\begin{array}{c}\text { Quantitative Data } \\
\text { Analysis }\end{array}$ & & \\
\hline & & \\
\hline Phase 2 & \multirow{4}{*}{$\begin{array}{l}\text { Development a semi- } \\
\text { structured questionnaire } \\
\text { - Key informant's selection } \\
\text { including university } \\
\text { lecturers, medical } \\
\text { employees, adolescents, } \\
\text { working-age adults, and } \\
\text { older adults } \\
\text { - Focus group discussion } \\
\text { - Take notes, summarize and } \\
\text { transcribe tapes }\end{array}$} & \multirow{4}{*}{$\begin{array}{l}\text { A semi-structured } \\
\text { questionnaire } \\
\text { - Transcribed of focus group } \\
\text { and note }\end{array}$} \\
\hline $\begin{array}{c}\text { Qualitative Data } \\
\text { Collection }\end{array}$ & & \\
\hline & & \\
\hline Qualitative Data Analysis & & \\
\hline & $\begin{array}{l}\text { - Content analysis } \\
\text { - Within and across-case } \\
\text { theme development } \\
\end{array}$ & $\begin{array}{l}\text { - Codes and theme } \\
\text { - Conceptual model of COVID- } \\
19 \text { preparedness and anxiety }\end{array}$ \\
\hline $\begin{array}{c}\text { Integration of } \\
\text { Quantitative Qualitative } \\
\text { Finding }\end{array}$ & $\begin{array}{l}\text { Integration and Explanation } \\
\text { of Quantitative Qualitative } \\
\text { Finding }\end{array}$ & $\begin{array}{l}\text { - Discussion } \\
\text { - Implication on practice } \\
\text { - } \text { Future research }\end{array}$ \\
\hline
\end{tabular}




\section{RESULTS}

\section{Quantitative Analysis}

The sample comprised $26.10 \%$ male, $72.27 \%$ female, and $1.43 \%$ transgender. Most of the participants $(28.56 \%)$ were $36-45$ years old, followed by $18-25$ years old $(24.11 \%)$, and $26-35$ years old $(19.37 \%)$. Most of them graduated with a bachelor's degree $(39.71 \%)$ and followed by a master's degree or higher (31.84\%). Their occupations included teachers, lecturers, academic employees (35.54\%), and followed by other occupations, i.e., corporate employees, homemakers, business owners, or retirees
(38.50\%). The majority $(24.64 \%)$ resided in southern provinces, followed by the three southern border provinces $(22.29 \%)$, and the Bangkok Metropolitan Region (18.34\%). Some of the participants stayed with households with (27.07\%) and without (32.30\%) children and older adults, which is as in Table 2. Most of them were living with adequate income to cover expenses but without excess for savings $(42.13 \%)$ and working from home or going off-house for weekly errands (45.62\%). However, some of the participants $(32.12 \%)$ were obligated to leave houses for work every day (Figure 2).

Table 2: Demographic characteristics of study sample $(n=2808)$.

\begin{tabular}{|c|c|}
\hline Variables & $\mathrm{n}(\%)$ \\
\hline \multicolumn{2}{|l|}{ Sex } \\
\hline Male & $733(26.10)$ \\
\hline Female & 2035 (72.47) \\
\hline Alternative gender & $40(1.43)$ \\
\hline \multicolumn{2}{|l|}{ Age } \\
\hline under 18 years & $103(3.67)$ \\
\hline $18-25$ years & $677(24.11)$ \\
\hline $26-35$ years & $544(19.37)$ \\
\hline $36-45$ years & $802(28.56)$ \\
\hline $46-55$ years & $433(15.42)$ \\
\hline over 56 years & $249(8.87)$ \\
\hline \multicolumn{2}{|l|}{ Education } \\
\hline Lower education & $799(28.45)$ \\
\hline Bachelor degree & $1115(39.71)$ \\
\hline Master degree or higher & $894(31.84)$ \\
\hline \multicolumn{2}{|l|}{ Occupation } \\
\hline Students & $631(22.47)$ \\
\hline Physicians, nurses, or medical profession & $98(3.49)$ \\
\hline Teachers, lecturers, or academic employees & $998(35.54)$ \\
\hline Others (e.g., corporate employees, homemakers, business owners, retirees) & $1081(38.50)$ \\
\hline \multicolumn{2}{|l|}{ Residing provinces } \\
\hline Bangkok and metropolitan & $515(18.34)$ \\
\hline North & $149(5.31)$ \\
\hline Central & $232(8.26)$ \\
\hline East & $94(3.35)$ \\
\hline North-Eastern & $434(15.46)$ \\
\hline West & $66(2.35)$ \\
\hline South & $692(24.64)$ \\
\hline Southern border provinces & $626(22.29)$ \\
\hline \multicolumn{2}{|l|}{ Family members } \\
\hline Without children or older adult & $907(32.30)$ \\
\hline With children but without older adult & $428(15.24)$ \\
\hline With older adult but without children & 713 (25.39) \\
\hline With children and older adult & $760(27.07)$ \\
\hline
\end{tabular}

Figure 2: Adequate income and conditions of work or off-house errands of study sample $(n=2808)$.

Adequate income

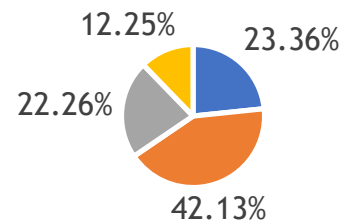

- Adequate income with excess for savings

- Cover expenses but without excess for savings

- Unstable

- Inadequate income to cover debts
Conditions of work or off-house errands

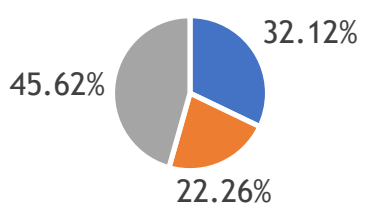

- Leave houses for work every day

- On shift or 2-3 times a week

- Worked from home or did weekly 
The factor analysis on COVID-19 preparedness revealed that the KMO value was 0.953 , the Approx. Chi-Square at the degrees of freedom of 276 was 29607.495 ( $p$-value $<0.01$ ), and the communalities ranged from 0.529-0.781. Six factors were extracted based on the cumulative covariance percentage exceeding 60 , which is as explained as $62.773 \%$ in Table 3 . The factors are explained in detail as follows:

Factor 1 - self-protection against risks: The factor is composed of five variables with a total variance explained of $39.047 \%$, a factor loading range of $0.544-0.743$, and an average variance extracted range of 4.41-4.66, indicating extremely high preparedness on all the variables. In general, the factor emphasized self-protection through observing symptoms, maintaining social distances, gathering relevant knowledge, and monitoring situations and news about local infections. Overall, it is about self-prevention against possible risks.

Factor 2 - information for family and community care: The factor is composed of six variables with a total variance explained of $7.613 \%$, a factor loading range of $0.479-0.669$, and an average variance extracted range of 3.96-4.45, indicating that most of the variables demonstrated extremely high preparedness (except for the variable on "spending free time during the outbreak on family activities"). This factor is revolved around care for family members through activities such as discussion about news as a process to relieve stress and worries as well as monitoring situations at local communities to gather useful information.

Factor 3 - cooperation in the fight against the pandemic: The factor is composed of four variables with a total variance explained of $4.907 \%$, a factor loading range of $0.505-0.816$, and an average variance extracted range of 3.32-4.12, indicating that three out of four variables were with high preparedness (except for the variable on "logging daily activities" which indicated moderate preparedness). These variables demonstrated cooperative efforts in combating against COVID-19 through the procurements of equipment to supply medical teams and the hospital, donations of cash and essential items, and attempts to contact medical personnel when exposed to risk factors. This cooperation reflects disciplines and attempts to reduce social burdens.

Factor 4 - maintaining physical and financial health: The factor is composed of three variables with a total variance explained of $4.023 \%$, a factor loading range of $0.528-0.715$, and an average variance extracted range of 3.93-4.38, indicating the variable on exercises as a mean to maintain healthy conditions was with high preparedness, whereas the remaining variables (including correct nutrition intakes and income and expense planning) demonstrated extremely high preparedness and indicated that unclear ends of the outbreak pressured citizens to strengthen themselves in two aspects, i.e., physical health and economic well-being.

Factor 5 - long-term outbreak mitigation planning: The factor is composed of three variables with a total variance explained of $3.856 \%$, a factor loading range of $0.506-0.814$, and an average variance extracted range of 3.46-3.65, indicating that all the variables were with high preparedness. These variables reflected long-term precautions that led to dietary preparation to strengthen immunity, purchases of COVID-19 life insurance packages, and seeking supplemental, alternative, or new careers to mitigate difficulties as the old ways of life have been shifted, and new norms have emerged.

Factor 6 - social immunity networks: The factor is composed of three variables with a total variance explained of $3.328 \%$, a factor loading range of $0.510-0.714$, and an average variance extracted range of 3.55-4.08, indicating that all the variables were with high preparedness as these variables involve social activities with acquaintances in and out of workplaces through the exchanges of information, providing social support, and giving or asking for consultations in the form of social network.

The factor analysis on COVID-19 anxiety revealed that the KMO value was 0.897, the Approx. ChiSquare at the degrees of freedom of 36 was 10672.431 ( $\mathrm{p}$-value < 0.01), and the communalities ranged from $0.598-0.783$. Three factors were extracted based on the Scree plot, with the cumulative variance percentage exceeding $70.521 \%$ (Table 3 ). The factors are explained in detail as follows:

Factor 1 - responses of the government and public sectors: The factor is composed of three variables with a total variance explained of $51.048 \%$, a factor loading range of 0.682 0.795 , and an average variance extracted range of $8.10-8.72$, indicating that anxiety towards the access to public health systems was high, whereas anxiety towards the lack of governmental and public responsibilities and the government's measures to reduce the spread of the government were at the highest levels. As the data were collected during the period that the citizens were clearly confused, the situation showed no signs of recovery, and global situations were alarming, anxiety hence emerged on an individual level and towards governmental actions.

Factor 2 - corruption and misconduct: The factor is composed of three variables with a total variance explained of $11.155 \%$, a factor loading range of 0.644-0.792, and an average variance extracted range of 7.94-8.75. The statistics indicated that anxiety towards fake news was high, and anxiety towards elevated crime rates, higher living expenses, and 
corrupt state policies was extremely high. It might not be too surprising that opportunists do exist in any situation.

Factor 3 - work and life: The factor is composed of three variables with a total variance explained of $8.317 \%$, a factor loading range of $0.701-0.748$, and an average variance extracted range of $7.37-8.23$. The statistics indicated that anxiety towards adequacy of consumer products, self-anxiety, anxiety towards subordinates, work anxiety, and educational anxiety was high. Anxiety towards economic situations (e.g., unemployment and income inadequacy) was extremely high. These levels reflected that the situation was being unpredictable, and citizens were anxious about what would occur to their work and lives during the outbreak.

Table 3: Factors of COVID-19 preparedness and anxiety in the Thai contexts.

\begin{tabular}{|c|c|c|c|}
\hline Items & $\begin{array}{l}\text { Factor } \\
\text { loading }\end{array}$ & Mean & $\begin{array}{l}\text { Standard } \\
\text { deviation }\end{array}$ \\
\hline Preparedness Factor 1 - self-protection against risks: & \multicolumn{3}{|c|}{$\begin{array}{c}\text { Eigenvalue }=9.371 \\
\text { Variance explained }=39.047\end{array}$} \\
\hline a1. Self-observation on symptoms (e.g., coughing, sore throat, physical pain, and fever, & 0.743 & 4.66 & 0.71 \\
\hline $\begin{array}{l}\text { a2. Monitoring of relevant announcements on infected patients or patients under investigation } \\
\text { across areas }\end{array}$ & 0.712 & 4.41 & 0.85 \\
\hline a3. Monitoring of public announcements on epidemiological news & 0.633 & 4.46 & 0.82 \\
\hline $\begin{array}{l}\text { a4. Maintaining social distances when contacting, talking, or doing activities with others in } \\
\text { daily life }\end{array}$ & 0.594 & 4.44 & 0.84 \\
\hline a5. Research for knowledge for outbreak-related mental preparation & 0.544 & 4.54 & 0.74 \\
\hline Preparedness Factor 2 - information for family and community care: & \multicolumn{3}{|c|}{$\begin{array}{c}\text { Eigenvalue }=1.827 \\
\text { Variance explained }=7.613\end{array}$} \\
\hline b1. Using leisure time during the outbreak to do activities with family members & 0.669 & 3.96 & 1.11 \\
\hline b2. Talking, consulting, and exchanging information with family members & 0.659 & 4.35 & 0.82 \\
\hline b3. Updating local news about the outbreak & 0.597 & 4.32 & 0.93 \\
\hline $\begin{array}{l}\text { b4. Planning or arranging houses or residential areas following relevant precautions for the } \\
\text { pandemic }\end{array}$ & 0.571 & 4.24 & 0.90 \\
\hline b5. Maintaining healthy mental conditions to relieve pandemic anxiety & 0.566 & 4.45 & 0.80 \\
\hline b6. Searching for pandemic-service information from the public and private sectors & 0.479 & 4.27 & 0.88 \\
\hline Preparedness Factor 3 - cooperation in the fight against the pandemic: & \multicolumn{3}{|c|}{$\begin{array}{c}\text { Eigenvalue }=1.178 \\
\text { Variance explained }=4.907\end{array}$} \\
\hline $\begin{array}{l}\text { c1. Agencies' provisions of medical assistance to citizens (e.g., patient transportation and } \\
\text { distributions of face masks, hand gel, and alcohol spray) }\end{array}$ & 0.816 & 3.73 & 1.29 \\
\hline c2. Subsidization on utilities, consumptions, or finance from government agencies & 0.801 & 3.56 & 1.33 \\
\hline c3. Logging daily activities & 0.579 & 3.32 & 1.30 \\
\hline $\begin{array}{l}\text { c4. Consideration on options when being exposed to risk factors for infection (e.g., contacting } \\
\text { with Village Health Volunteers, or nurses with personal connections or from nearby hospitals) }\end{array}$ & 0.505 & 4.12 & 1.03 \\
\hline Preparedness Factor 4 - maintaining physical and financial health: & \multicolumn{3}{|c|}{$\begin{array}{c}\text { Eigenvalue }=0.966 \\
\text { Variance explained }=4.023\end{array}$} \\
\hline d1. Choosing nutritious meals to cope with the outbreak & 0.715 & 4.38 & 0.82 \\
\hline d2. Exercising in limited spaces to stay healthy & 0.689 & 3.93 & 1.10 \\
\hline d3. Planning on income and expenditure for the outbreak & 0.528 & 4.25 & 0.93 \\
\hline Preparedness Factor 5 - long-term outbreak mitigation planning: & \multicolumn{3}{|c|}{$\begin{array}{c}\text { Eigenvalue }=.926 \\
\text { Variance explained }=3.856\end{array}$} \\
\hline e1. Studying about and purchasing COVID-19 life insurance packages & 0.814 & 3.49 & 1.40 \\
\hline e2. Preparation for supplemental, alternative, new careers or planning to start a new life & 0.644 & 3.46 & 1.32 \\
\hline e3. Consumption of vitamins or herbs to stimulate the immune system & 0.506 & 3.65 & 1.27 \\
\hline Preparedness Factor 6 - social immunity networks: & \multicolumn{3}{|c|}{$\begin{array}{c}\text { Eigenvalue }=0.799 \\
\text { Variance explained }=3.328\end{array}$} \\
\hline $\begin{array}{l}\text { f1. Talking and exchanging information with colleagues or close friends to prepare for the } \\
\text { outbreak }\end{array}$ & 0.714 & 4.08 & .98 \\
\hline $\begin{array}{l}\text { f2. Talking to, consulting with, or persuading acquaintances to buy products to prepare for } \\
\text { the outbreak }\end{array}$ & 0.706 & 3.55 & 1.16 \\
\hline $\begin{array}{l}\text { f3. Planning to participate in social-service activities (e.g., volunteering and fundraising in the } \\
\text { time of the outbreak) }\end{array}$ & 0.510 & 3.57 & 1.19 \\
\hline Anxiety Factor 1 - responses of the government and public sectors: & \multicolumn{3}{|c|}{$\begin{array}{c}\text { Eigenvalue }=4.594 \\
\text { Variance explained }=51.048\end{array}$} \\
\hline a1. Anxiety towards the lack of public responsibilities & 0.795 & 8.64 & 1.73 \\
\hline a2. Anxiety towards access to public health systems & 0.775 & 8.10 & 1.99 \\
\hline a3. Anxiety towards governmental measures in reducing the outbreak & 0.682 & 8.72 & 1.83 \\
\hline Anxiety Factor 2 - corruption and misconduct: & \multicolumn{3}{|c|}{$\begin{array}{c}\text { Eigenvalue }=1.004 \\
\text { Variance explained }=11.155\end{array}$} \\
\hline $\begin{array}{l}\text { b1. Anxiety towards corruption from government policies or delays in aids and recoveries in } \\
\text { all sectors }\end{array}$ & 0.792 & 8.63 & 1.95 \\
\hline $\begin{array}{l}\text { b2. Anxiety towards social changes (e.g., rises of crime, consumption expenses, and } \\
\text { transportation fees) }\end{array}$ & 0.758 & 8.75 & 1.73 \\
\hline b3. Anxiety towards the management of fake news & 0.644 & 7.94 & 2.27 \\
\hline Anxiety Factor 3 - work and life: & \multicolumn{3}{|c|}{ Variance explained $=8.317$} \\
\hline c1. Anxiety towards current or further education of the participants or children & 0.748 & 7.93 & 2.51 \\
\hline c2. Anxiety towards the adequacy of consumer goods & 0.732 & 7.37 & 2.25 \\
\hline $\begin{array}{l}\text { c3. Anxiety towards possible impacts from economic conditions that might occur to the } \\
\text { participants or their families (e.g., unemployment and income inadequacy) }\end{array}$ & 0.701 & 8.23 & 2.51 \\
\hline
\end{tabular}


The canonical correlation analysis was conducted to examine the relationships between the six factors of COVID-19 preparedness (i.e., selfprotection against risks, information for family and community care, cooperation in the fight against the pandemic, maintaining physical and financial health, long-term outbreak mitigation planning, and social immunity networks) and the three factors of COVID-19 anxiety (i.e., responses of the government and public sectors, corruption and misconduct, and work and life). Results indicated that there were four canonical equation functions. However, only the first two showed statistical significance at the 0.01 level, and Function 1 demonstrated the highest canonical correlation $\left(R_{C}\right)$ of 0.403 with a Wilks' Lambda of 0.779, a Chi-Square of 697.25 (p-value < 0.01) at the degrees of freedom of 18 . The canonical correlation $\left(R_{C}\right)$ of Function 2 was 0.260 with a Wilks' Lambda of 0.931 and a Chi-Square of 200.95 ( $p$-value $<0.01$ ) at the degrees of freedom of 10 . Function 1 indicated that the canonical correlation between the two factors was $16.24 \%$, whereas Function 2 suggested that the canonical relationship between the two variables was as low as $6.76 \%$. Hence, while Function 1 explained the correlation at a moderate level, Function 2 demonstrated a low level according to the criteria of Chianchana ${ }^{32}$.
When using the cutoff value of 0.45 based on Sherry and Henson ${ }^{33}$ with the structure coefficients in Function 1, it was found that the factors of "self-protection against risks" and "long-term outbreak mitigation planning" were correlated with COVID-19 preparedness through the factor of "responses of the government and public sectors." Furthermore, the factor of "corruption and misconduct" was correlated with COVID-19 anxiety through the factors of "selfprotection against risks" and "long-term outbreak mitigation planning" with the proportions of variance explained of $60.8 \%$ and $21.1 \%$ respectively. The factor of "responses of the government and public sectors" and "corruption and misconduct" were with the proportions of variance explained of $55.5 \%$ and $37.7 \%$, respectively. These correlations show that Canonical Function 1 could explain that citizens who were highly prepared for "self-protection against risks" and "long-term outbreak mitigation planning" tended to congruently demonstrate high anxiety towards "responses of the government and public sectors" and "corruption and misconduct." As exhibited in Figure 3, however, these results indicated that the structure coefficients are equal to the canonical coefficients on standard coefficients since this factor analysis employed factor scores.

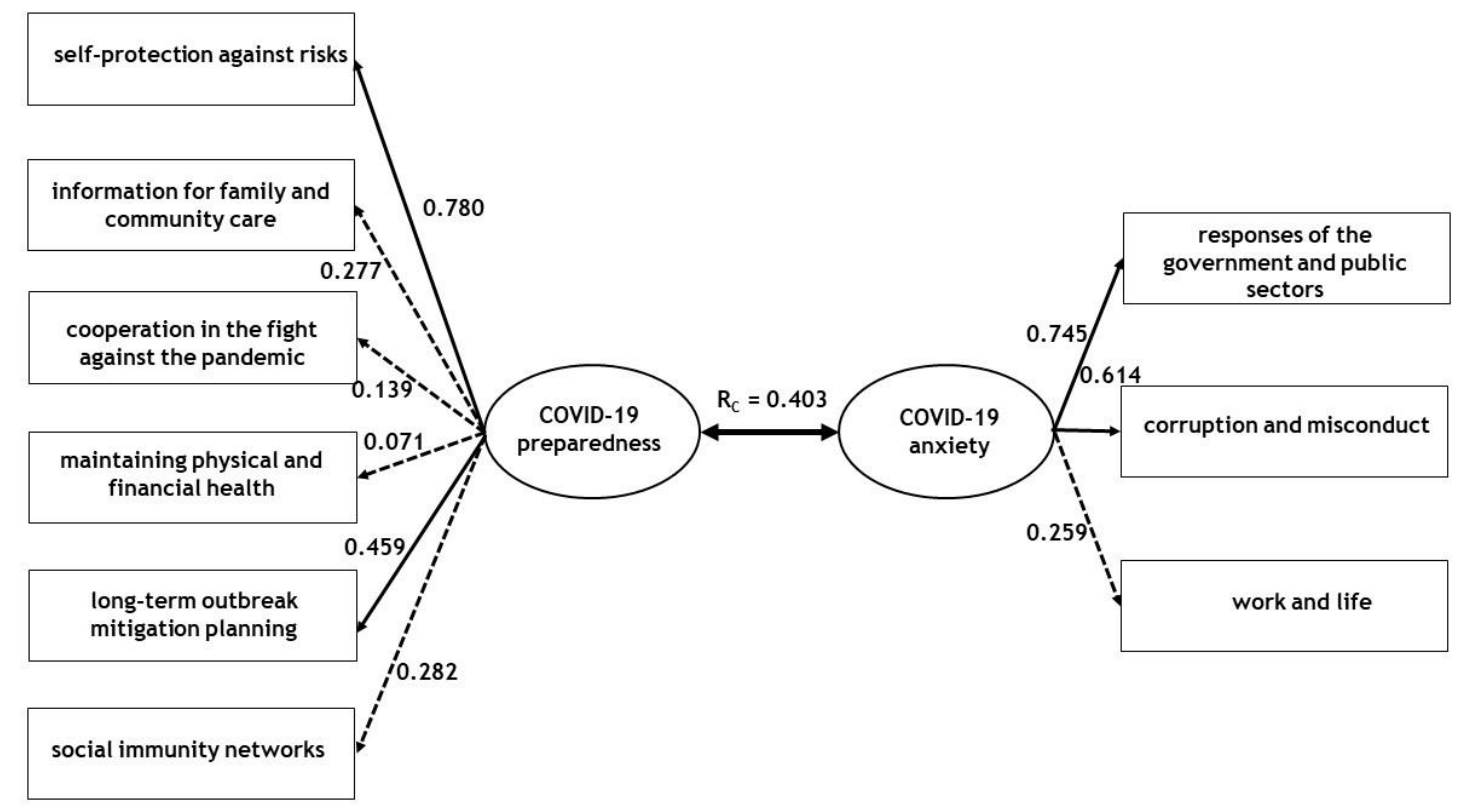

Figure 3: The relationship between COVID-19 preparedness and anxiety in the Thai contexts.

\section{Qualitative Analysis}

Focus group discussions were conducted. Each group session involved a presentation of the quantitative data analysis and the first question (How significant and correlated are COVID-19 preparedness and anxiety?). The first group contained five lecturers in higher education with experiences in crisis-related research. These participants contributed by addressing that cooperation was key to safeguarding against the outbreak. At the personal level, self-protection should be taken to reduce risks. At the family and community level, relevant information should be obtained to care for families and surrounding communities. At the social level, a social immunity network should be formed. The second group contained four medical professionals on duties to handle the outbreak. They indicated that priorities should go to preserving physical health. The third group included two teenagers, 
two adults, and two older adults, who were willing to provide information and affected by the lockdown. They perceived that, in addition to well-maintained physical health, financial adequacy was another crucial factor in surviving this crisis. The results of the three groups were found not in conflict.

The results derived from the focus group discussions were constructed into the conceptual model framework on COVID-19 preparedness to comprise six factors based on the three levels of outbreak preparedness. 1) The individual level included Factor 1 on self-protection against risks (e.g., self-observation on symptoms, gathering knowledge for outbreak-related preparation, monitoring of epidemiological news, and maintaining social distances in daily activities). 2) The family and community level included Factor 2 on information for family and community care (e.g., talking, consulting, or exchanging information and news with family members, planning or arranging house conditions, spending leisure time with family members, and searching for pandemic-service information from the public and private sectors). 3) The social network level included Factor 6 - social immunity networks: (e.g., talking to, exchanging information with, and or persuading colleagues and close friends to buy products or prepare for the outbreak, and planning to participate in social-service activities). All the three levels could be combined to form a bigger picture that reflects the three factors of cooperation in the fight against the pandemic (e.g., governmental provisions of medical assistance or subsidization on utilities, consumptions, and finance for citizens and logging daily activities). Since the cure is unknown and vaccines are unavailable to relieve situations of this emerging disease, Factor 5 on long-term outbreak mitigation planning became significant (e.g., as citizens studied about and purchasing COVID-19 life insurance packages, took vitamins to enhance immunity, and prepared for supplemental, alternative, or new careers). Furthermore, the above results were also correlated with tremendous changes in ways of life as reflected in Factor 4 as the citizens attempted to maintain physical and financial health, e.g., by opting for nutritious meals, staying healthy with exercises, and planning on income and expenditure for the outbreak (see Figure 4).

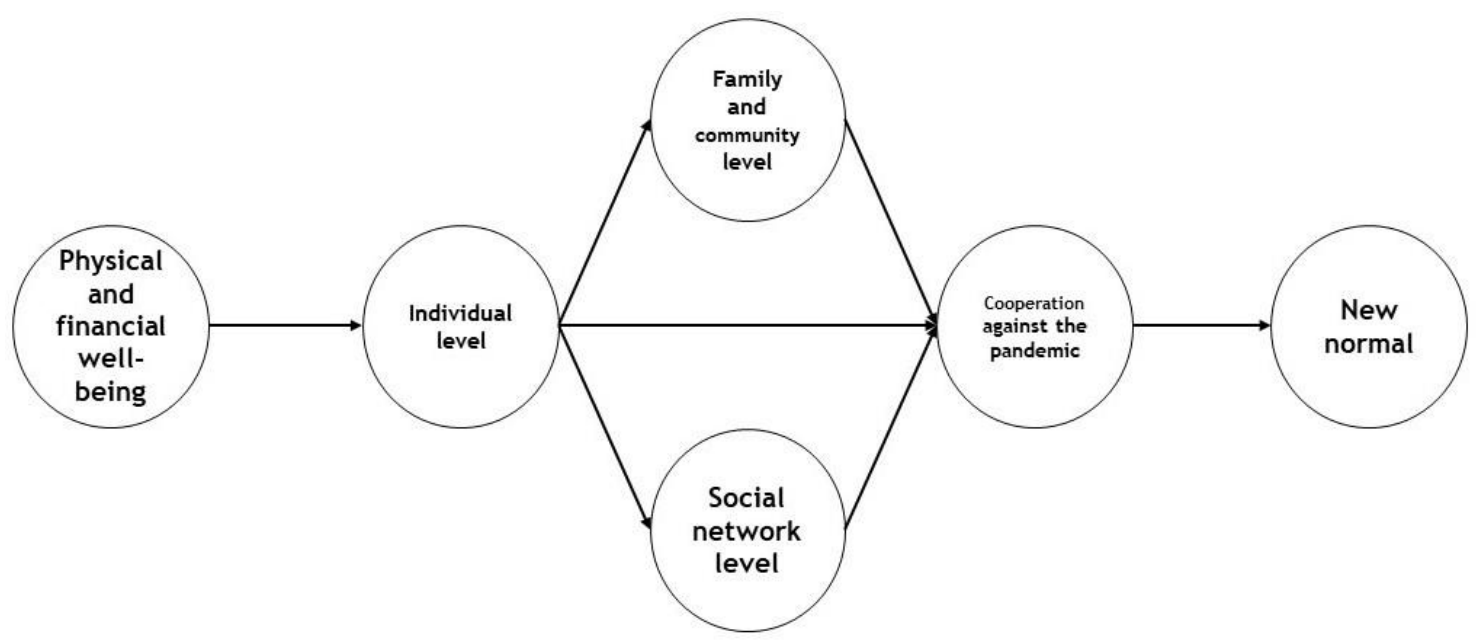

Figure 4: The conceptual model framework on COVID-19 preparedness.

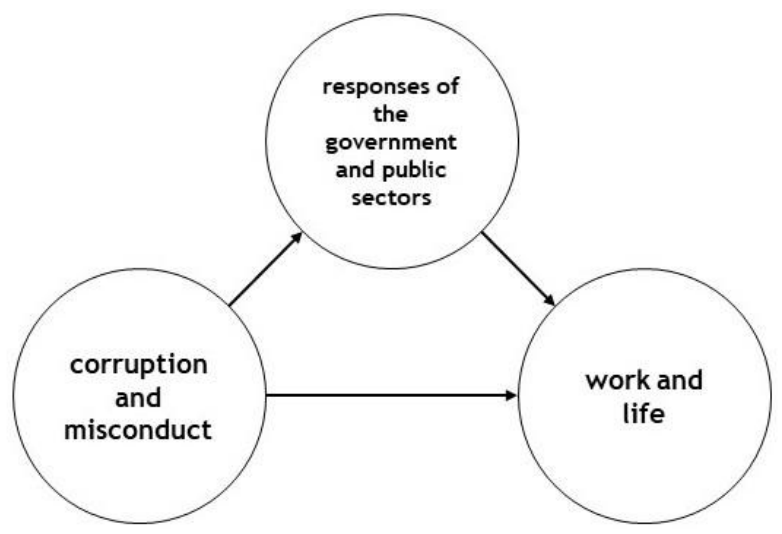

Figure 5: The conceptual model framework on COVID-19 anxiety. 
Moving on to the second question (How substantial and correlated are COVID-19 anxiety and rates of spread?), those in the lecturers' group stated that factors related to corruption, misconduct, and the state's abilities and the people to handle the situation influenced the operations and the livelihoods. Relevant agencies should observe operational transparency to alleviate this situation. Members of the medical professionals' group raised similar inputs and added that the lack of transparency and good governance would negatively impact the state's and the people's mitigation efforts. Such barriers would complicate operations and unnecessarily introduce new problems on top of the existing ones. Members of the group with youths, adults, and older adults reported that corruption and misconduct were the causes of difficulties and would only stir up anxiety towards the COVID-19 coping. Furthermore, the constructed conceptual model framework on COVID-19 anxiety in the Thai contexts based on the focus group discussions comprised three factors, including corruption and misconduct, as well as responses of the government and public sectors and both factors have direct impacts on work and life anxiety (see Figure 5). This correlation indicates that when the authorities are engaged in corruption and misconduct in the care for public health, such behaviors would degrade the responses of the government and public sectors and boost COVID19 anxiety, especially on work and life due to social and economic pressure. This notion was especially true with the cases on access to disease-prevention facilities, the lockdown duration lacking clarity, the state's damage control, children's forced school breaks, workers' work-from-home readiness, online systems lacking revisions, income impacts from outbreak-led job suspensions, job losses, and outbreak-related costs.

Regarding the third question (What should be the appropriate self-practice guidelines to follow amid the COVID-19 outbreak, new normal, and next normal?), all three groups provided similar inputs, presented in two levels. 1) In cases where the situation could be controlled, screening must be required to separate patients with COVID-19 and healthy individuals. Reporting of information should be transparent to ensure appropriate follow-up actions. Systematic restoration of livelihood and economy should be expedited. Necessary supplies for the prevention of COVID-19 should be provided, such as surgical masks, fabric masks, and alcohol. 2) In cases where the outbreak was not contained, regional lockdown measures should be taken in coordination with relevant parties, such as public administrative bodies, the military, the police, local administrative organizations, and public health agencies, to ensure that there is a tangible area control against the pandemic.

\section{DISCUSSION}

The results indicated that most of the participants worked at home or went away from home for weekly errands (45.62\%). However, some of them $(32.12 \%)$ were obligated to leave their residential areas for work every day, and their outbreak preparedness was high or extremely high with mean scores ranging from 3.32-4.66. The sample group paid attention to self-observation for symptoms, maintained healthy mental conditions, sought knowledge on the pandemic, monitored national news of the situation, and gave cooperation in maintaining social distances. Nevertheless, their outbreak anxiety was high or extremely with mean scores ranging from 7.378.75. Their anxiety was towards government measures, which were specifically about delayed remediations and restoration, increased consumption costs, unemployment, income inadequacy, crimes, and poor public responsibility. These results are consistent with Roy et al which discovered that Indian citizens were committed to following governmental guidelines on quarantines and social distancing as well as possessed high levels of anxiety. Furthermore, over $80 \%$ of these citizens were preoccupied with the COVID-19 outbreak ${ }^{12}$. Wang et al found that $84.7 \%$ of the Chinese citizens spent 20-24 hours at home during the outbreak. Many reportedly had moderate to severe psychological effects (53.8\%), developed symptoms with moderate to severe depression, (16.5\%), and demonstrated moderate to critical levels of anxiety (28.8\%) and stress (8.1\%), respectively ${ }^{13}$. Congruently, they are also in line with the survey results by Prince of Songkla University Pattani Campus, which discovered that $91 \%$ of the respondents were anxious since they were overwhelmed with the news ${ }^{11}$. Similar results were published by Zhang and $\mathrm{Ma}$ as it reported that most of the Chinese citizens in Liaoning were slightly depressed from the outbreak, and only $7.6 \%$ demonstrated severe depression ${ }^{14}$.

The quantitative analysis of COVID-19 preparedness in the Thai contexts comprised six factors, as discussed in the research results and based on the conceptual model framework of qualitative analysis on COVID-19 preparedness, these factors could be categorized into three levels:

1) The individual level that includes Factor 1 on self-protection against risks. (e.g., observing symptoms, maintaining social distances, gathering relevant knowledge, and monitoring situations and news about local infections)

2) The family and community level that includes Factor 2 on information for family and community care. (e.g., discussion about news as a process to relieve stress and worries, and monitoring situations at local communities to gather useful information) 
3) The social network level that includes Factor 6 - social immunity networks (e.g., the exchanges of information, providing social support, and giving or asking for consultations in the form of social network).

All the three levels could be combined to form a bigger picture that reflects by Factor 3 on cooperation in the fight against the pandemic such as procurements of equipment to supply medical teams, donations of cash and essential items, and attempts to contact medical personnel when exposed to risk factors. Since the cure is unknown and vaccines are unavailable to relieve situations of this emerging disease, Factor 5 on long-term outbreak mitigation planning became significant such as preparation to strengthen immunity, purchases of COVID-19 life insurance packages, seeking supplemental or new careers to mitigate difficulties as the old ways of life have been shifted, and new norms have emerged. Furthermore, these results were also correlated with tremendous changes in ways of life, as reflected in Factor 4 as the citizens attempted to maintain physical and financial health.

Hence, the results could be firstly related to the main guidelines that the Thai Ministry of Public Health issued under the slogan titled "stay home, stop the infection, for the nation" 26 , secondly the announcement to that labeled COVID-19 as a dangerous communicable disease following the Communicable Disease Act 2015 dated on March $5,2020^{25}$, and thirdly the governmental Invocation of the Emergency Decree 2005 which led to the initiation of curfew measures or bans from leaving residential areas from 10 p.m. to 4 a.m. since April 3, $2020^{34}$. Similarly, the number of infected and hospitalized patients tended to decline (as of June 4, 2020, Thailand had 75 active cases with $2,968(95.71 \%)$ recovered cases from 3,101 accumulated confirmed cases $^{35}$. Consequently, national outbreak preparedness is an indicator that reflects how ready a country is in handling the crisis. As Dr. Trosros Adhanom Ghebreyesus (WHO's Director-General) discussed on Twitter on March 25, 2020: "History will judge us on how we responded to the poorest communities in their darkest hour. Let us act together, right now"36. The above analysis of Thais' preparedness might reflect that they were satisfactorily prepared for the new/next normal, especially on selfprotection against risks and long-term planning against the disease contributed to the cooperation in carrying out designed state measures. The results also related with the disaster preparedness classification of MalkinaPykh in three categories refer to 1) Material Preparedness, 2) Planning Activities, and 3) Knowledge and Skills, respectively ${ }^{20}$.

As described in the quantitative and qualitative analysis of COVID-19 anxiety in the Thai contexts indicates that when the authorities are engaged in corruption and misconduct in the care for public health, such behaviors would degrade the responses of the government and public sectors and boost COVID-19 anxiety, especially on work and life due to social and economic pressure, and could be discussed as follows:

1) Corruption and misconduct (e.g., anxiety towards corruption from government policies, delays in aids and recovery efforts, increased consumption expenses, and rise in criminal actions): During this period, there was a shortage of alcohol to be used to prevent infection, and consumer goods were stockpiled. As in Bangkok Business, several artists and celebrities donated consumer items and cash to hospitals. In addition, there were many other groups, in similar natures, who tried to aid those in need, e.g., restaurant volunteers who ran a campaign titled "giving away free food," and hotel volunteers who gave up their accommodations to construct temporary field hospitals ${ }^{28}$. Amid positivity, however, there has been news from media on the disappearance of 200 million masks which caused a senior civil servant (i.e., the Director-General of the Department of Internal Trade, Ministry of Commerce) in charge to be suspended from duties and transferred to the Prime Minister's Office on March 15, 202037-40. Nevertheless, this official was already permitted to resume the former position ${ }^{41}$, and this inconsistency is also another example of fake news and confusion generated by the news society of Thailand ${ }^{42}$.

2) Responses of the government and public sectors (e.g., anxiety towards the lack of public responsibilities, access to public health systems, and governmental measures in reducing the outbreak): Consistently with Posttoday, apart from managing situations at the local level and promoting social distancing, measures should be in place to campaign for proactive protection, foster understanding, encourage public cooperation, push for timely identification of patients, case investigation, and hospitalization, as well as revitalize community-level economic foundations ${ }^{43}$. Similarly, Amnesty International Thailand demanded that stakeholders such as governments, individuals, and organizations in all nations, should check whether COVID-19 mitigation measures respect international laws and standards on human rights by taking into account the specific needs of the marginalized and the vulnerable. Furthermore, corrections should be made if such risks of human 
rights violations were found resulting from epidemiological measures ${ }^{44}$.

3) Work and life (e.g., anxiety towards the adequacy of consumer goods, possible changes in economic landscapes, and current and further education of the citizens and their children): The above results confuse citizens in many aspects including daily life, traveling, work, university teaching, and use of restaurant services. Subsequently, the Thai government ordered to prohibit crossprovincial travels in Thailand from April 1 to May 30, 2020, except for medical or authorized personnel ${ }^{34,45}$. The agencies that were most significantly affected included those who are in the education sector as they were forced to conduct online teaching. Currently, the government sector via the Ministry of Education ordered educational service providers for elementary and secondary education to perform their teaching online from June 1, 2020, and in-class instructions would resume on July $1,2020^{46}$. Furthermore, the Ministry of Higher Education, Science, Research, and Innovation decided to employ blended instructions by combining regular offline and new online learning together, reducing instructional time, alternate learning days, and find solutions to appropriately arrange field studies, practices, and internship ${ }^{47}$. Nonetheless, these measures reflect social inequality based on differences in the capacities of instructors, students, and parents. As reported in Bangkokbiznews, the phenomenon presented new challenges that the Thai and global societies are facing ${ }^{48}$.

The results of the three factors are also consistent with Egunjobi, which conducted an online survey on COVID-19 fear by involving participants in 11 countries, most of whom being Nigerians. Results showed that the participants perceived COVID-19 as a form of biological weapon $(29.2 \%)$ and a divine punishment $(19.8 \%)$. As many as $77 \%$ of the participants were moderately or highly frightened of the disease. Furthermore, fear factors were found associated with economic constraints, unemployment rates, rises of crime, and possibilities for World War III ${ }^{49}$. Similarly, Presti et al classified the dynamics of fear into three courses: 1) anxiety-derived fear, especially towards COVID-19 as being discussed here during this period which could pressure people to escape from affected areas, 2) disruption to the sense of self, e.g., spending time finding detailed information, discussing in search for clarifications, as well as repeated thinking and reviewing on what is correct or incorrect, and 3) prejudices and discrimination, e.g., the case when Corona Beer, with a resembling name to Coronavirus, innocently received negative impacts, or as this virus was originated in China, Asians were, reportedly in media, affected from prejudice ${ }^{50}$. Concerning the anxiety over the COVID-19 situation, Deeod reflected that stateled measures were delayed, and the public had difficulties accessing them. Therefore, it was proposed that the government should distribute financial aids alongside other measures. The above analysis on Thais' anxiety showed that corruption, misconduct, and the state's abilities and the people to handle the situation contributed a large portion of the weight on generating anxiety. On the other hand, workrelated anxiety, especially on sustaining personal lives and family members, was less influential since it was a controllable factor. Therefore, having a systematic and effective plan would easily resolve the situation as many Thais are competent followers and practitioners during the crisis $^{16}$.

Although this study was able to explain the canonical correlation between the factors of COVID-19 prepared and anxiety at $16.24 \%$ probably because of the involvement of new factors causing COVID-19 prepared and anxiety to be moderately correlated, these correlations could explain that citizens who were highly prepared for "self-protection against risks" and "long-term outbreak mitigation planning" tended to congruently demonstrate high anxiety towards "responses of the government and public sectors" and "corruption and misconduct." One thing that was reflected through the relationship in Figure 4 is that Thai citizens were aware of and understood that during this outbreak, self-reliance is most crucial. This outbreak is not based on factors such as social classes, statuses, or wealth. Instead, it spreads through the air, which is a public commodity. Also, the disease generally takes longer before the infected show symptoms (approximately 5 - 21 days), causing the course of this situation to be longer than other crises that the global community has ever encountered. In terms of anxiety, it can be seen that the variables on "responses of the government and public sectors" and "corruption and misconduct" were given importance as they both could affect longterm outbreak mitigation and readiness for "selfprotection against risks."

The above results are in line with the data from the focus group discussions that until cure or vaccine is available, every sector must cooperate to protect work-life well-being from the spread of infection, i.e., by wearing fabric or surgical masks, maintain 1.5-2 meters in social distancing, frequently and properly wash hands at home and work with soap, prepare and use alcohol spray or gel when being outside, maintain healthy conditions and strengthen immunity through the consumption of hygienic food containing all five categories of nutrition, and do regular exercises which are as recommended by $\mathrm{WHO}^{51}$ and other local guidelines for local citizens in many countries, e.g., Thailand $\mathrm{d}^{52}$ and Malaysia ${ }^{53}$ on living strategies to escape COVID-19. However, Citizens 
are suggested to protect themselves, families, workplaces, communities, and societies in a prioritized order, and the top priority should go to self-care. Citizens should take preventive measures to slow the spread of the outbreak, even though they are not susceptible to infection. More specifically, when they are in a public area, or a crowded location, surgical or fabric face masks should be worn, hands should be washed suitably based on applicable cleaning principles, pay attention to the symptoms they or surrounding people might have, consume healthy meals, exercise with suitable areas with precautions, avoid socializing and going to high-risk areas, stay tuned to news and updates about COVID-19 from domestic and international sources, and cooperate with government, agencies, and local bodies when precautionary measures are available. As time progresses, further studies should repeat data collection to confirm the conceptual model framework on COVID-19 preparedness in conjunction with anxiety and compare results across population groups in different countries (e.g., China, South Korea, Singapore, Taiwan, and Malaysia). Limitations of this study as the results were projected to adequately reflect the situation in the period of January to March 2020. After the data were collected, the government promulgated the Emergency Decree, and the epicenter of the COVID-19 pandemic have shifted from China to Italy, Spain, and the United States. Hence, various data began to fluctuate rapidly and might have also impacted the outbreak preparedness and anxiety to some extent.

\section{CONCLUSION}

COVID-19 preparedness in the Thai contexts was scoped into three levels, i.e., individuals, families and communities, and social networks. The new normal influenced by cooperation in the fight against the pandemic and also became an additional variable for these three levels. Through new normal, physical and financial well-being was deemed to be the prime focus. The anxiety has become deeply rooted and correlated with the spread of COVID-19 of Thai society. It began with a lack of confidence in the handling of corruption and misconduct by responsible parties, and responsibility of the government and public sectors. Hence, the situations created direct impacts on the well-being of the Thai citizens.

\section{ACKNOWLEDGEMENTS}

The authors would like to thanks to all of the respondents and many thanks to the peer reviewers in the Malaysian Journal of Public Health Medicine for providing constructive and insightful feedback to improve this manuscript.

\section{Funding: None}

Conflict of interest: None

\section{REFERENCES}

1. Suwannik S. How will the world change? After the crisis of the Covid-19 ended? https: / /www.bot.or.th/Thai/ResearchAn dPublications/articles/Pages/Article_30M ar2020.aspx [Assessed 2020 May 30].

2. Ali S, Asaria M, Stranges S. COVID-19 and inequality: are we all this together? Can J Public Health. 2020; 111: 415-416.

3. McGreal C. The inequality virus: How the pandemic hit America's poorest. https: / / www. theguardian.com/world/20 20/apr/09/america-inequality-laid-barecoronavirus [Assessed 2020 November 23].

4. Fagherazzi G, Goetzinger C, Rashid MA, Aguayo GA, Huiart L. Digital health strategies to fight COVID-19 worldwide: Challenges, recommendations, and a call for papers. J Med Internet Res. 2020; 22(6): e19284.

5. Hassan TA, Hollander $S$, van Lent $L$, Tahoun A. Firm-level exposure to epidemic diseases: Covid-19, SARS, and H1N1. https: / /www.nber.org/papers/w2 6971.pdf [Assessed 2020 May 30].

6. Atkeson A. What will be the economic impact of COVID-19 in the US? Rough estimates of disease scenarios. https: / / www.nber.org/papers/w26867.p df [Assessed 2020 May 30].

7. Suwanprasert W. COVID-19 and endogenous public avoidance: Insights from an economic model. https://ideas.repec.org/p/pui/d paper/128.html [Assessed 2020 May 30].

8. Bai Y, Lin CC, Lin CY, Chen J, Chue $C M$, Chou $P$. Survey of stress reactions am ong health care workers involved with the SARS outbreak. Psychiatr Serv. 2004; 55(9 ), 1055-1057. https://doi.org/10.1176/ap pi.ps.55.9.1055

9. Lau JT, Yang X, Tsui HY, Pang E, WinG YK . Positive mental health-related impacts o $f$ the SARS epidemic on the general public in Hong Kong and their associations with 0 ther negative impacts. J. Infect. 2006; 53 (2): 114-124. https://doi.org/10.1016/j.j inf.2005.10.019

10. Peng EYC, Lee MB, Tsai ST, Yang CC, Mori sky DE, Tsai LT, Weng YL, Lyu SY. Population-based post-crisis psycholo gical distress: An example from the SARS outbreak in Taiwan. J. Formos. Med. Asso c. 2010; 109(7), 524-532. https://doi.org /10.1016/ S0929-6646(10)60087-3. 
11. Prince of Songkla University Pattani Campus. Survey results on measures and cooperation in surveillance of the COVID19.

https: / /administration.pn.psu.ac.th/prfile/21Aprilnews.pdf [Assessed 2020 April 22].

12. Roy D, Tripathy S, Kar SK, et al. Study of knowledge, attitude, anxiety \& perceived mental healthcare need in Indian population during COVID-19 pandemic. Asian J. Psychiatry. 2020; 51:1-7. https://doi.org/10.1016/j.ajp.2020.1020 83

13. Wang C, Pan R, Wan X, et al. Immediate psychological responses and associated factors during the initial stage of the 2019 Coronavirus Disease (COVID-19) epidemic among the general population in China. Int. J. Env. Res. Pub. Health. 2020; 17(5):1-25.

https://doi.org/10.3390/ijerph17051729

14. Zhang M, Ma ZF. Impact of the COVID-19 pandemic on mental health and quality of life among local residents in Liaoning province, China: A cross-sectional study. Int. J. Env. Res. Pub. Health. 2020; 17(7):1-12.

https://doi.org/10.3390/ijerph17072381

15. Lekfuangfu WN, Piyapromdee S, Porapakkarm P, Wasi N. On Covid-19: New implications of job task requirements and spouse's occupational sorting. https://papers.ssrn.com/sol3/papers.cf m?abstract_id=3583954 [Assessed 2020 May 30].

16. Deeod P. The impact spread of the Coronavirus 2019 (COVID-19) on occupation of a food delivery service. Journal of MCU Nakhondhat. 2020; 7(6): 131-144.

17. Suwanaphant K, Seedaket S, Vonok L, Assana S, Wawngam W, Kingsawad K, OnKail $P$. Factors associated with stress due to corona virus disease 2019 (COVID-19) pandemic among students of the Faculty of Public Health and Allied Health Sciences, Praboromarajchanok Institute. Journal of Health Science. 2020; 14(2): 138-148.

18. Wae A. COVID-19 and learning to change behavior in health today. Journal of The Health Education Professional Association. 2020; 35(1); 24-29.

19. Kleechaya P. Urbanites' accessibility, understanding, evaluation and application of health information for their selfcare in international spreading of emerging infectious disease. Report Research of Health System Research Institute (HSRI); 2018.

http: / /164.115.27.97/digital/files/origin al/6146d0dd1385e905faad6822bcdf5773. pdf [Assessed 2020 November 23].

20. Malkina-Pykh IG. An integrated model of psychological preparedness for threat and impacts of climate change disasters. The III International Conference on Disaster Management and Human Health: Reducing Risk, Improving Outcomes. C.A. Brebbia (Ed.), WIT Press, Southampton, 2013; 121 133.

21. Swift P, Cyhlarova E, Goldie I, O'Sullivan, C. Living with Anxiety: Understanding the role and impact of anxiety in our lives. London: Mental Health Foundation; 2014.

22. Hauksdottir A, Steineck G, Furst CJ, Valdimarsdottir U. Long term harm of low preparedness for a wife's death from cancer: A population-based study of widowers 4-5 years after the loss. American Journal of Epidemiology. 2010; 175(4): 389-396.

23. Cagle JG, Kovacs PJ. Informal caregivers of cancer patients: perceptions about preparedness and support during hospice care. Journal of Gerontological Social Work. 2011; 54(1): 92-115.

24. Mutianingsih, Mustikasari, Panjaitan RU. Relationship between psychological preparedness and anxiety among elderly in earthquake prone areas. Enfermería Clínica. 2020; 30(3): 45-48.

25. Government Gazette. Ministry of Public Health on names and important symptoms of dangerous communicable diseases (Issue 7). 2020; 137(48d), p.1.

26. Ministry of Public Health. Stay at home, stop the infection, for the nation. https://www.moph.go.th/index.php/ne ws/read/1700 [Accessed 22 ${ }^{\text {th }}$ February 20].

27. Daily News. Do it yourself easily! Hand wash gel anti-virus helper "COVID-19". https: //dailynews.co.th/bangkok/757940 [Accessed 30 $0^{\text {th }}$ March 20].

28. Bangkok Business. Volunteer spirit "Thai people do not leave each other" in the crisis of COVID-19, we must survive. https: / /bangkokbiznews.com/news/deta il/872635 [Assessed 2020 March 20].

29. Creswell JW, Clark VLP. Designing and conducting mixed methods research. 3rd 
ed. Los Angeles: SAGE Publications; 2018.

30. Department of Provincial Administration. Announcement of the Central Registration Office regarding the number of citizens throughout the Kingdom. http://stat.dopa.go.th/stat/statnew/ups tat_age.php [Assessed 2020 April 20].

31. National Statistical Office. Information and communication technology survey of households.

http://www.nso.go.th/sites/2014/Pages /News/2561/N26-10-61.aspx [Assessed 2020 March 20].

32. Chianchana C. Using multivariate statistics for research: Designing, analyzing, and interpreting. Bangkok: King Mongkut's University of Technology North Bangkok; 2015.
33. Sherry A, Henson RK. Conducting and interpreting canonical correlation analysis in personality research: A user-friendly primer. J. Pers. Assess. 2005; 84(1):37-48.

34. Government Gazette. Public Administration in Emergency Situations 2005 (Issue 2). 2020; 137(76d), p.1.

35. Department of Disease Control. COVID-19 situation report. https: / / covid19.ddc.moph.go.th/ [Assessed 2020 June 4].

36. Twitter. Launch of the COVID10 global humanitarian response plan with DrTedros.

https: / / twitter.com/WHO/status/124282 1614426882054 [Assessed 2020 April 22]. 